\title{
The Effect of Aural and Visual Storytelling on Vocabulary Retention of Iranian EFL Learners
}

\author{
Maryam AminAfshar ${ }^{1} \&$ Ahmad Mojavezi ${ }^{1}$ \\ ${ }^{1}$ English Language Department, Zahedan Branch, Islamic Azad University, Zahedan, Iran \\ Correspondence: Ahmad Mojavezi, Department of English, Zahedan Branch, Islamic Azad University, Zahedan, \\ Iran. E-mail: a.mojavezi@gmail.com
}

\author{
Received: January 14, 2017 Accepted: March 12, 2017 Online Published: March 14, 2017 \\ doi: 10.5539/elt.v10n4p92 URL: http://doi.org/10.5539/elt.v10n4p92
}

\begin{abstract}
EFL learners at all ages and proficiency levels are usually confronted with various problems in vocabulary learning and retention. This study sought to introduce strategies for improvement of vocabulary learning and retention. Therefore, the effects of using aural/visual storytelling on Iranian EFL learners' vocabulary learning and retention were investigated. To do so, 50 intermediate female EFL learners were randomly assigned to two groups. After the administration of teacher made English Vocabulary Test as the pre-test, aural storytelling method was used for the control group, and visual storytelling method was used for the experimental group. After three months of instruction, the aforementioned teacher made English Vocabulary Test, as the post-test, was given to the students of both groups to assess their improvements. Two weeks after post-test, they were given a delayed post-test to measure their retention of English vocabulary knowledge. The reliability of the English Vocabulary Test using Cronbach's Alpha was estimated equal to 0.80. Finally, Using ANCOVA, the results revealed that, the experimental group's participants outperformed those of control group in both learning and retention of English vocabulary. So, it can be noted that the training program according to visual could have impressive impact on the learning and retention of vocabulary knowledge.
\end{abstract}

Keywords: vocabulary, vocabulary retention, storytelling

\section{Introduction}

Vocabulary expansion is a continuous method where students engage the words several times in their training to improve and develop their information and their usage of words in the foreign language (Cameron, 2001). Word memorization is also promoted by employing essential exercises to study vocabulary as it presents students with chances to learn words effectively, which indicates that this cannot be accomplished favorably if they just repeat them orally by drilling or by utilizing flashcards. Actions which involve learners in thinking about words and making judgments about them allow students to remember words efficiently.

Perhaps the greatest tool that second or foreign language learners can use to succeed not only in their education but also in their lives is a rich vocabulary stock. The most prominent goal of every language learner is to gain autonomy in using appropriate language in an authentic communication in which lack of good vocabulary knowledge will ultimately lead to communication breakdown (Gardner, 2011).

During the last century, approaches, methodologies and techniques in the area of second language teaching and learning have repeatedly changed. In every period, new language teaching methods with the claim of effectiveness have emerged assigning much responsibility on L2 teachers to try and evaluate them for their students.

An effective way to help learners learn the L2 vocabulary is to introduce strategies for learning vocabulary. Schmitt (1997) defines vocabulary learning strategies as "the processes by which information (word knowledge) is obtained, stored, retrieved, and used".

The more common problems of students at all ages and proficiency levels are meaningful vocabulary learning, retention and recalling. Rote memorization of vocabulary results in poor performance in the communicative use of vocabularies. Contextualized story telling is one of the best strategies to propose meaningful learning context to learners (Brown \& Tomlinson, 1993).

Based on Jahangard (2007), oral and aural skills are not concentrated in Iranian EFL textbooks. Therefore, this 
study aimed at exploring the effects of aural and visual storytelling technique on vocabulary learning and retention of EFL learners, because it is suggested that implementing storytelling activities such as visual aids may help improve the young learners' vocabulary learning in the EFL classes and foster the retention of vocabulary items.

This study, thus, benefits the attractiveness of aural and visual storytelling technique - especially for young learners- and vocabulary learning strategy to examine the rate of word retention. It was an attempt to discover whether teaching L2 vocabulary through the use of aural and visual storytelling technique including visual aids would help the young Iranian EFL learners acquire the new vocabulary items in the target language. The specific research questions this study sets out to answer are:

Is there any significant difference across aural and visual storytelling techniques on vocabulary learning of intermediate Iranian EFL learners?

Is there any main variation across aural and visual storytelling techniques on vocabulary retention of intermediate Iranian EFL learners?

\section{Literature Review}

Macaro's study (2003) showed that second language instructors view vocabulary as a subject they most require study to shed light on to increase the education and studying in their classes. Accordingly, it might be declared that the role of vocabulary in L2 learning is quickly identified and implications for education from the substantial study are in high demand.

\subsection{Empirical Background}

The history of storytelling has followed various ways in different cultures. Hui-Ling Huang (2006) investigated the effects of contextualized storytelling on EFL young readers' reading comprehension and vocabulary retention. Drawing on Dual-Code Model and the multiple sensory approaches, it was hypothesized that the multi-sensory method, with the aid of storytelling, will be a useful intervention than Dual-code Form in EFL reading and vocabulary recognition.

Elaf. S. Abdulla (2012) surveyed the importance of using storytelling as a new technique in vocabulary teaching/learning. English language learners faced many problems in learning vocabulary since they have to memorize a large stock of vocabularies day by day.

Soltani, et al (2015) in a study investigated the effect of using pictorial storytelling as a new technique in language teaching. It is related to what the students watch, listen, and think. It examined in a pre and posttest quasi experimental design. The result of their study confirmed that pictorial storytelling helped improvement of vocabulary learning for EFL learners.

A study by Sadeghi, K., and Farzizadeh, B. (2013) studied the vocabulary training additions of beginner EFL learners in the Iran Language Institute (Urmia branch) utilizing the use of visual attention and the conventional procedure of definition. The findings suggested a wealth of opportunity for teachers to undergo the visual-supported method for teaching.

A study by Hemmati, et al (2013) and Yu, (2011) compared the impacts of two approaches of game playing and storytelling on Iranian EFL kindergartner learners' vocabulary identification as well as the systems' superiority across each other. According to the results of an analysis of within subjects' impacts and an independent t-test, it was achieved that both the techniques were efficient and story - based group did somewhat better.

According to Mauro Dujmovic (2014) storytelling is the art of relating a tale from memory rather than reading it is one of the oldest of whole art forms, related to prehistoric times. Moreover, storytelling can produce a motivating and low stress context for language training.

\section{Methodology}

\subsection{Participants}

This study was carried out with the participation of 50 female intermediate students studying at Roshd girls' high school in Zahedan, Iran. Their ages range from 15 to 16 years old. All of them were native speakers of Persian the same native tongue is necessary to avoid any cultural differences and make the results as reliable as possible. They attended English classes two sessions per week, each for a period of one and a half hour. In order to increase the validity and avoid any cultural and social differences all of the participants were selected from the same school to be similar in social, cultural, economic and academic level. 


\subsection{Instruments}

The assessment materials that were used included a teacher made test of English vocabulary. pre-test, post-test were the same, and delayed post-test had the same format and same questions but displayed the test items in a different order was administrated to measure their retention of English vocabulary. The teacher made 40-item vocabulary recognition test, this test consisted of multiple-choice and matching, each of which tested one single vocabulary. It is worth mentioning that for the multiple-choice items, the students had to either find the most appropriate word from among the alternatives to complete the stem, and for matching items they had to choose the best synonym or antonym.

It is also valuable to mention that, the reliability of the English Vocabulary Test consisting of 40 items using Cronbach's Alpha was estimated as 0.80 .

To guarantee the content validity of the test, the researcher consulted and checked the items of the test with two university instructors, and to reduce the instructor effect on learning outcome, we as a same procedure for two gropus.

\subsection{Storytelling}

Storytelling is a tool for the expression of actions, emotions, and opinions in various modes of transfer and dating back to ancient times notwithstanding all the advanced creativity. This approach, which has converted a refined tool in presenting opinions and experiences with the support of the mass media, has become notable in all areas of investigations as well as TEFL (Soltani et al., 2015). It can be used as a proper tool for memorizing and using the words for the children.

\subsubsection{Storytelling Presents a Story}

Storytelling is always engaged with the narration of a story. Much other art styles also offer story, though storytelling offers it with the other four elements. Every culture has its explanation of the story. What is acknowledged as a story in one state may not be affirmed as one in another. Some conditions call for inspiration and playful variation, for instance; others call for near-exact repetition of a respected text (Soltani et al., 2015).

\subsubsection{Storytelling Activates the Alive Imagination of the Listeners}

In storytelling, the listener imagines the story. The storytelling listener's task is to produce the vivid, multi-sensory images actively, actions, characters, and events - the reality —of the story in mind, according to the performance by the teller and the listener's past actions, beliefs, and thoughts. The formed story happens in the mind of the hearer, a novel, and personalized individual. The listener becomes as a co-creator of the story as encountered. Storytelling can be mixed with other art styles. The fruit born by the vital, contemporary storytelling movement involves the development of ways to integrate storytelling with drama, comedy, dance, music, puppetry, and numerous other modes of representation (Soltani et al., 2015).

\subsubsection{Vocabulary Retention}

Vocabulary retention is expressed as "the ability to recall or remember things after an interval of time. For this purpose the learners tested in to times including immediate test, and a delayed test which is carried out two weeks later. Learners do not usually memorize a new word as soon as they learn it for the first time. Memorizing a new word requires a process: getting the word form; meaning; consolidating word form and meaning in memory; using the word in conversations.

In language teaching, retention of what has been taught (e.g. grammar rules and vocabulary) may depend on the quality of teaching, the interest of the learners, or the meaningfulness of the materials" (Richards \& Schmidt, 2002 , p. 457). As it is clear in the area of vocabulary learning, the difficulty is not just in learning the second language; rather in remembering. Bahrick (1984) argues that how well people remember anything related to how intensely they treat it. Hence, the different method has been suggested to promote vocabulary retention. Focusing on characteristics of the new word and its textual context is supposed to promote retention. Learning in context related to repeating, recycling, and representing vocabularies as well as re-noticing them by the student. It has been proposed (e.g. Haastrup, 1989; Modria \& Wit-de Boer, 1991; Xialong, 1988, as cited in Hedge, 2000) that recognition depends on the situation in which the meaning is inferred and the more examination included, the better the retention. Also, memory depends on some way on the amount of mental and emotional energy utilized in preparing a word and readers have developed certain strategies that could help emotional and rational processing.

\subsection{Procedures of Data collection \& Data Analyses}

The first phase of this study was the pilot phase during which 25 intermediate students with similar features to 
the target sample took the test. The researcher conducted item analysis and reliability estimate of the 60 -item vocabulary test, through which 20 malfunctioning items were omitted and the Cronbach Alpha came out to be 0.80 .

In the second phase of this study the participants were selected. First, the English Vocabulary Test was administered to 75 intermediate students to homogenize them regarding their general English proficiency. Out of 75 students, 50 students (females) whose scores had fallen one standard deviation above and below the mean shaped the main participants of the study.

The selected participants were randomly assigned to two groups of experimental and control group, the control group was taught the new English vocabulary aurally, for example teacher repeated the new vocabulary and students repeated after him. In the experimental group vocabulary was presented through visual methods such a showing the stream of story through pictures and using diagram, flashcard and pictures to show the meaning of the new words, after that the treatment period is started. Considering the fact that the syllabus of the language school had to be covered during the semester, ten sessions of 30 minutes were allocated to the experiment. Therefore, the classes of control and experimental groups received the same hours of instruction and practice. Also the researcher himself taught the two groups. Both experimental and the control group enjoyed the same course book, materials, vocabularies, and passages.

At the end of the semester, the learners in the experimental and control groups received the post-test of English vocabulary which aims at finding out the vocabulary improvement among the learners. This is the time immediately after the instruction session

Two weeks later, they were given a delayed post-test which has the same format and same questions but arranged the test items in a different order to measure their retention of English vocabulary knowledge.

The data was collected through pre-test, post-test and delayed post-test in order to answer the research questions. Each correct answer was received one point. Wrong responses were not given penalties.

The results of both tests were analyzed using the SPSS for Microsoft windows 22. First, the data of the post-test for each group was analyzed separately in order to find the mean and standard deviation of the scores in each group. The same procedure was followed with the scores of the delayed posttest. ACOVA was employed to show differences in learning and retention of English vocabulary in the two groups. The hypotheses were tested at the 0.05 level of significance.

\section{Results and Discussion}

\subsection{Research Hypothesis 1}

$\mathrm{H} 0$ : There is no significant relationship between aural and visual storytelling techniques on vocabulary learning of intermediate Iranian EFL learners.

The first research question investigated the effect of using aural and visual storytelling technique on vocabulary learning of intermediate Iranian EFL learners. To answer this question, the researcher conducted an ANCOVA analysis of the groups scores from the pre-test and the post-test.

One of the required assumption to use ANCOVA is the homogeneity of variances. Thus, Levene's test of equality of variance was done to check the assumption that the dependent variable will have similar variances for all groups. The results of the Levene's test for homogeneity of variance are reported in Table 1 below.

Table 1. Test of equality of variance on posttest scores in experimental and control groups

Levene's Test of Equality of Error Variances ${ }^{a}$

\begin{tabular}{llll}
\hline $\mathrm{F}$ & $\mathrm{df1}$ & $\mathrm{df2}$ & Sig. \\
\hline 0.046 & 1 & 48 & 0.831 \\
\hline
\end{tabular}

After that the researcher estimated the statistical descriptive of the scores as shown in Table 2 below. 
Table 2. Descriptive Statistics of the Participants' Performance on the Vocabulary pretest and posttest

Group Statistics

\begin{tabular}{llllll}
\hline & Group & N & Mean & Std. Deviation & Std. Error Mean \\
\hline \multirow{2}{*}{ pretest } & Pretest of experimental & 25 & 25.1600 & 1.21381 & 0.24276 \\
& Pretest of control group & 25 & 27.8800 & 1.23558 & 0.24712 \\
\hline \multirow{2}{*}{ posttest } & Posttest of experimental & 25 & 31.5200 & 1.19443 & 0.23889 \\
& Posttest of control group & 25 & 28.4800 & 1.15902 & 0.23180 \\
\hline
\end{tabular}

As the descriptive statistics show in Table 2 the mean score of the experimental group in pretest was 25,16 but the mean score of the control group was 27.88 , it shows that there was a preexisting differences among two groups. But in posttest the mean scores of experimental changed to 31.52 and control group change to 28.48 . In order to see whether this difference was statistically significant, the researcher conducted an ANCOVA analysis, the results of which is presented in Table 3 below.

Table 3. ANCOVA Analysis of the vocabulary knowledge Pre/Post-Test Scores

Tests of Between-Subjects Effects

\begin{tabular}{lllllll}
\hline Source & Type III Sum of Squares & df & Mean Square & F & Sig. & Partial Eta Squared \\
\hline Corrected Model & $115.522^{\mathrm{a}}$ & 2 & 57.761 & 40.837 & $<.05$ & .635 \\
Intercept & 91.136 & 1 & 91.136 & 64.433 & $<.05$ & .578 \\
pretest & .005 & 1 & .002 & .001 & .972 & .05 \\
Group & 51.022 & 1 & 51.022 & 36.072 & $<.05$ & .434 \\
Error & 66.478 & 47 & 1.414 & & & \\
Total & 45182.000 & 50 & & & & \\
\hline Corrected Total & 182.000 & 49 & & & & \\
\hline
\end{tabular}

a. R Squared $=.635$ (Adjusted R Squared $=.619$ ).

As it is indicated in Table 3 there is a statistically significant difference between the performance of the experimental and control groups, $(\mathrm{F}=36.07,<.05)$. Since $\mathrm{P}$ value is lower than .05 , the first null hypothesis is rejected and the positive influence of visual storytelling technique and improvement of intermediate Iranian EFL learners' learning of vocabulary in the target language was confirmed.

Therefore, it can be said that the training program based on visual could have positive effects on the experimental groups' learning the vocabulary. The findings of this study support the studies mentioned in the literature. These findings confirm that the experimental group's mean score was greater than that of control group due to the teaching procedures. Therefore, it can be said that the visual-based instruction can positively affect learning of English vocabulary by the Iranian EFL intermediate learners.

\subsection{Research Hypothesis 2}

H0: There is no significant relationship between aural and visual storytelling techniques on vocabulary retention of intermediate Iranian EFL learners.

The focus of enquiry in the second research question was to seek whether there was any significant difference among the vocabulary retention scores of those EFL learners who use visual and audio methods in learning of vocabulary item. To find a clear answer for this research question a one-way ANCOVA was conducted considering the delayed posttest scores as the dependent variable, posttest scores as the covariate. In the next step, Levene's test of equality of variance was done to checks the assumption that the dependent variable will have similar variances for all groups. The results of the Levene's test for homogeneity of variance are reported in Table 4. 
Table 4. Test of equality of variance on posttest scores in experimental and control groups

Levene's Test of Equality of Error Variances ${ }^{\mathrm{a}}$

\begin{tabular}{lllll}
\hline $\mathrm{F}$ & $\mathrm{df1}$ & $\mathrm{df2}$ & Sig. \\
\hline 2.453 & 1 & 48 & .124 \\
\hline
\end{tabular}

Then, the researcher estimated the statistical descriptive of the scores as shown in Table 5.

Table 5. Descriptive statistics of the participants' performance on the vocabulary posttest and delayed posttest

Group Statistics

\begin{tabular}{llllll}
\hline & Group & N & Mean & Std. Deviation & Std. Error Mean \\
\hline \multirow{2}{*}{ posttest } & posttest of experimental & 25 & 31.5200 & 1.19443 & 0.23889 \\
& posttest of control & 25 & 28.4800 & 1.15902 & 0.23180 \\
\hline \multirow{2}{*}{ delayed posttest } & Delayed posttest of experimental & 25 & 30.3200 & 1.02956 & 0.20591 \\
& Delayed posttest of control & 25 & 25.4400 & 1.60935 & 0.32187 \\
\hline
\end{tabular}

According to Table 5 the mean scores of the experimental group in posttest was 31,52 but the mean score of the control group was 28.48. But in delayed posttest the mean scores of experimental decreased to 30.32 and control group to 25.44. So, it can be concluded that the scores of control group decreased greatly compared to experimental group in delayed posttest. In order to see whether this difference was statistically significant, the researcher conducted an ANCOVA analysis, the results of which is presented in Table 6 below.

Table 6. ANCOVA Analysis of the vocabulary knowledge post/delayed post-test scores

Tests of Between-Subjects Effects

\begin{tabular}{lllllll}
\hline Source & $\begin{array}{l}\text { Type III Sum of } \\
\text { Squares }\end{array}$ & df & Mean Square & F & Sig. & $\begin{array}{l}\text { Partial } \\
\text { Squared }\end{array}$ \\
\hline Corrected Model & $297.858^{\mathrm{a}}$ & 2 & 148.929 & 80.068 & $<.05$ & 0.773 \\
Intercept & 63.894 & 1 & 63.894 & 34.351 & $<.05$ & 0.422 \\
posttest & 0.178 & 1 & 0.178 & 0.096 & 0.758 & 0.05 \\
Group & 115.858 & 1 & 115.858 & 62.288 & $<.05$ & 0.570 \\
Error & 87.422 & 47 & 1.860 & & & \\
Total & 39250.000 & 50 & & & & \\
\hline Corrected Total & 385.280 & 49 & & & &
\end{tabular}

a. R Squared $=0.773$ (Adjusted R Squared $=0.763$ )

As above table shows there is a statistically significant difference between the performance of the experimental and control groups in delayed posttest, $(\mathrm{F}=62.28,<.05)$. Since $\mathrm{P}$ value is lower than .05 . And the second null hypotheses is rejected. So, it is clear that using visual storytelling improve intermediate Iranian EFL learners' retention of vocabulary in the target language.

The result revealed that there was a significant difference between experimental and control group. The experimental group outperformed the control group.

There has been very little work on the impact of visual and audio on short term and long term memorization in general. By the way, these findings are also in line with those of literature.

\section{Conclusion and Implications}

The main conterbioution of this research is to Based on the results and discussion held previously, the use of proposed visual story telling could improve the mastery of the elementary students' knowledge of English 
vocabulary. The improvement could also be observed statistically through the comparison of the students' mean score in the pre-test, post-test and to delayed post-test for both the control and experimental group. Students were learning with visual storytelling, which made them engaged positively in all learning activities.

Furthermore, the consequences of the delayed posttest confirm that utilizing visual story telling in education vocabulary did have a meaningful impact on the long-term memory of the vocabulary items related to conventional techniques of vocabulary learning. In fact, recognition of vocabulary in control group reduced apparently in contrast to the experimental one in the range of time. Also, learners attain this procedure pleasant and effective in EFL vocabulary learning objects.

Numerous scholars said that children can benefit from listening to storytelling (Alna, 1999; Ellis, 1997; Erikson, 1995). Using the technique of storytelling in the classroom allows the modeling of language patterns. Also, Children who are exposed to aural and visual storytelling on a regular basis over a period of several months show significant gains in reading comprehension, decoding skills, and vocabulary. Furthermore, Outcomes of this study offer implications for policy makers, teachers and teacher educators. The recommendations that can be drawn from the foregoing conclusions and implications are (a) educational policy-makers should attend to the usefulness of the visual storytelling in Iran school subjects context, (b) new methodological developments should be taken into consideration by EFL teachers, (c) EFL teachers should receive training in applying visual storytelling principles, local FL textbook writers should work along visual storytelling lines, (d) to find ways to facilitate the adaptation of the visual storytelling to Iran EFL classroom and thereby enhance studentś opportunities to speak English fluently and accurately, and (e) this study was administrated in Roshd girls' high school in Zahedan, this design are recommended in other cities of Iran.

\section{References}

Alna, O. (1999). The importance of oral storytelling in literacy development. The Ohio reading teacher, 31(1), 15-18.

Bahrick, H. P. (1984). Semantic memory content in permastore: Fifty years of memory for Spanish learned in school. Journal of Experiment Psychology: General, 113(1), 1-31. https://doi.org/10.1037/0096-3445.113.1.1

Brown, D. H., \& Tomlinson, H. (1993). Effects of nitrogen salts on lichen physiology. Bibliotheca Lichenologica, $53,27-34$.

Cameron, L. (2001). Teaching languages to young learners. Cambridge: Cambridge University Press. https://doi.org/10.1017/CBO9780511733109

Dujmovic, S. C. M. (2014). Pregledni rad UDK: 371.3:811.111-26 Storytelling as a Method of EFL Teaching, Visoka uciteljska škola, Pula.http://hrcak.srce.hr/file/17682

Elaf, S. A. (2012). The Effect of Storytelling on Vocabulary Acquisition.

Ellis, B. F. (1997). Why tell stories? Storytelling Magazine, 9(1), 21-23.

Erikson, M. (1995). Why stories? School arts, 94(7), 38-39.

Gardner, H. (2011). Frames of mind: The theory of multiple intelligences: Basic books.

Hedge, T. (2000). Teaching and learning in the language classroom. Oxford: Oxford University Press.

Hemmati, F., Teimoori, M., \& Jafarigohar, M. (2013). A Comparison of Effect of Pictorial Storytelling and Playing Games on Iranian Kindergartens' Vocabulary Recording. International Journal of Language Learning and Applied Linguistics World, 165.

Hui-Ling, H. (2006). The Effects of Storytelling on EFL Young Learners' Reading Comprehension and Word Recall, English Teaching \& Learning. National Yunlin University of Science and Technology, 30(3), 51-74.

Jahangard, A. (2007). Evaluation of EFL materials taught at Iranian public high schools. The Asian EFL Journal, $9(2), 130-150$.

Macaro, E. (2003). Second language teachers as second language classroom researchers. Language Learning Journal, 27(1), 43-51. https://doi.org/10.1080/09571730385200071

Richards, J. C., \& Schmidt, R. (2002). Longman dictionary of language teaching and applied linguistics (3rd Ed.). London: Pearson Education.

Sadeghi, K., \& Farzizadeh, B. (2013). The Effect of Visually-Supported Vocabulary Instruction on Beginner EFL Learners' Vocabulary Gain. Mextesol Journal, 37(1), 1-12. 
Schmitt, N. (1997). Vocabulary learning strategies. In N. Schmitt, \& M. McCarthy (Eds.), Vocabulary: Description, Acquisition, and Pedagogy (pp. 199-227). Cambridge: Cambridge University Press.

Soltani, N., Khalaji, H. R., \& Azizmalayeri, F. (2015). The Effect of Pictorial Storytelling on the Development of Vocabulary Learning of Iranian EFL Primary Learners. International Journal of Educational Investigations, 2 (1), 239-248.

Yu, L. (2011). Vocabulary Recognition and Memorization: A Comparison of Two Methods, Kristianstad University, School of Teacher Education, English, Level IV English.

\section{Copyrights}

Copyright for this article is retained by the author(s), with first publication rights granted to the journal.

This is an open-access article distributed under the terms and conditions of the Creative Commons Attribution license (http://creativecommons.org/licenses/by/4.0/). 